\title{
EXPRESSÕES NEGATIVAS NA FALA DE UMA CRIANÇA BRASILEIRA E UMA CRIANÇA FRANCESA: ESTUDO DE CASOS
}

\author{
Angelina NUNES DE VASCONCELOS* \\ Ester SCARPA** \\ Christelle DODANE***
}

- RESUMO: O trabalho é um estudo longitudinal de duas crianças, uma brasileira e uma francesa, e focaliza o desenvolvimento das expressões de negação na fala das duas. Objetiva mostrar que, no início, nas instâncias a que chamamos de "protonegações", marcadas por gesto e vocalização, são indissociáveis e assumem sentido na interpretação do outro. As funções das primeiras partículas negativas produzidas pela criança foram construídas a partir do sistema de classificação sóciopragmática das negações desenvolvido por Beaupoil-Hourdel (2013). As seguintes categorias são consideradas: rejeição/recusa; expectativas insatisfeitas; ausência/desaparição; proibição/ comando; oposição/correção; rogativa negativa; negação epistêmica; negação funcional. Os resultados mostram que a rejeição/recusa é a primeira função a emergir na fala de ambas as crianças, ao passo que a ausência/desaparição é mais tardia. A complexificação progressiva das negações produzidas pelas duas crianças podem depender da inclusão de pronomes pessoais em seus enunciados, bem como da introdução de variações nas partículas negativas utilizadas. Por outro lado, ações e vocalizações infantis auxiliam na delimitação de um todo significativo, mesmo com um léxico bastante restrito.

- PALAVRAS-CHAVE: Aquisição da linguagem. Negação. Prosódia. Português. Francês.

\section{Introdução}

O presente artigo focaliza as características de expressões de negação produzidas por uma criança brasileira e também por uma criança francesa dos 11 aos 32 meses de vida, em situação de interação com seus pais. O estudo do desenvolvimento da

\footnotetext{
* Universidade Federal de Alagoas (UFAL), Instituto de Psicologia, Maceió - AL - Brasil. angelina.vasconcelos@ ip.ufal.br. ORCID: 0000-0003-4376-4740

** Universidade Estadual de Campinas (UNICAMP), Instituto de Estudos da Linguagem, Campinas - SP - Brasil. ester. scarpa@gmail.com. ORCID: 0000-0002-9021-4285

**** Université Paul Valéry, Montpellier 3. Sciences du Langage, Institut des Technosciences et de la Communication (I.T.I.C.). Laboratoire Praxiling, Montpellier - Paris - França. christelle.dodane@gmail.com. ORCID: 0000-00023733-1263
} 
negação é relevante por ser esta uma instância privilegiada para observação da trajetória linguística, inicialmente através de gestos e vocalizações (durante o primeiro ano de vida) e, posteriormente, através do surgimento dos primeiros marcadores verbais de negação (BEAUPOIL-HOURDEL; MORGENSTERN; BOUTET, 2016).

Vasconcelos (2013) e Vasconcelos e Leitão (2016) investigaram as chamadas condutas proto-opositivas, isto é, ações produzidas pela criança ao longo do primeiro ano de vida, como choro e gestos, que foram interpretadas pelos adultos como oposição a desejos, vontades, propósitos e comandos. No presente trabalho, as características das produções negativas adultas e infantis da díade brasileira e francesa são investigadas, com foco nas características das protonegações. O prefixo 'proto' marca o caráter precursor das produções infantis (gestuais e vocais) em curso de desenvolvimento, as quais são interpretadas pelos adultos como protestos, oposições e negações. São estas produzidas antes dos primeiros não/non, entre 6 e 19 meses de idade. Com as primeiras lexicalizações na fala da criança, verificamos as diferentes funções negativas ${ }^{1}$ produzidas pelas crianças (ordem de surgimento, relação entre as diferentes funções, entonações e gestos específicos). A atenção ao período chamado proto-linguístico, que antecede o estabelecimento de léxico inicial, busca demonstrar que, mesmo neste período, há modulações vocais, ou seja, variações em altura, duração e intensidade, que potencialmente integram a construção dos significados opositivos nesta fase inicial de aquisição.

\section{"Pré-linguagem"}

Desde seu nascimento (e ainda antes, na vida intrauterina) os bebês estão em contato constante com a língua falada em seu entorno, desenvolvendo progressivamente a capacidade de compreender e posteriormente produzir esta língua (BOYSSONBARDIES, 1996; NAME, 2011). Nesse processo, adultos e criança ajustam-se mutuamente, mesmo antes do surgimento das primeiras palavras, realizando trocas comunicativas organizadas prosodicamente. Desde muito cedo, o adulto dirige-se ao bebê fazendo uso de linguagem com características diferenciadas.

Ainda no útero, por exemplo, o bebê é capaz de captar os sons da fala da mãe e ainda no primeiro ano de vida, processá-los, discriminando mudanças prosódicas ou no ordenamento de elementos (DECASPER et al., 1994; NAME, 2011; BOYSSONBARDIES, 1996). A precocidade do processamento prosódico, voltado a características de sua língua materna, é igualmente afirmado em outros resultados de pesquisas (FRIEDERICI; FRIEDRICH; CHRISTOPHE, 2007; NAZZI; JUSCZYK; JOHNSON, 2000), e supõe-se que tal capacidade seja fortemente relevante para a aquisição da linguagem no segundo ano de vida.

Como veremos adiante, elas são: rejeição/recusa; expectativas insatisfeitas; ausência/desaparição; proibição/ comando; oposição/correção; rogativa negativa; negação epistêmica; negação funcional. 
Já do ponto de vista da produção, embora a fixação de etapas restritas relacionadas à idade cronológica seja difícil de ser realizada, o processo de desenvolvimento da linguagem é comumente separado em dois grandes momentos supostamente delimitados: o "pré-linguístico", caracterizado por vocalizações reflexas como suspiros, bocejos e choro e pela produção de sons que se assemelham a nasais e vogais; e o período "linguístico" quando a criança começaria a produzir o balbucio chamado "tardio", caracterizado pela emissão não-sistemática de vocalizações e sílabas básicas, em trechos de extensão e prosódia variável, e um léxico inicial, vinculado a configurações morfosintaticamente reconhecíveis como tais pela comunidade de fala.

Este esquema geral de desenvolvimento termina por postular certa descontinuidade entre os períodos 'pré'e 'linguístico', delimitando o primeiro ano de vida enquanto etapa preliminar ao desenvolvimento da linguagem no qual a criança somente aperfeiçoaria mecanismos de percepção e produção de fala. Contudo, trabalhos apontam a continuidade entre o balbucio e as primeiras palavras produzidas pela criança (VIHMAN, 1992; BOYSSON-BARDIES; HALLÉ; SAGART; DURAND, 1989), observando a existência de uma 'protolíngua' já em desenvolvimento. Estes trabalhos sugerem que este período vem sendo insuficientemente descrito. É esse período que a literatura contempla como proto-linguagem, aquele que antecede imediatamente a fase linguística propriamente dita (BLOOM, 1970). Assim é que alguns pesquisadores mostram como bebês de apenas nove meses de idade são capazes de produzir características rítmicas e entonacionais de sua língua materna (KONOPCZYNSKI, 1990, 1991). A partir dos 9 meses, o bebê já reproduz as configurações melódicas semelhantes foneticamente às das frases interrogativas, enunciativas e exclamativas de sua comunidade de fala, apresentando, portanto, um contraste entonacional básico (DODANE, 2015), embora tal semelhança fonética não indique necessariamente a mesma sistematicidade dos tons que caracteriza a fala da criança depois da introdução de um léxico primitivo (SCARPA, 1988; SCARPA; FERNANDES-SVARTMAN, 2012).

Investigando especificamente a emergência da negação, Dodane e Massini-Cagliari (2010) afirmam que a prosódia permite à criança posicionar-se na interação antes da emergência de marcadores morfossintáticos de negação e que, no momento da aparição destas marcas, complementa e dá suporte aos demais níveis linguísticos ainda insuficientemente desenvolvidos. Dodane e Martel (2009) já tinham relatado que, em produções de duas crianças francesas ainda mais jovens - 10 a 12 meses, observa-se diminuição na duração silábica e na média de $\mathrm{F}^{\circ}$, concluindo que a criança desde muito cedo regula suas produções.. Estas produções passam a ser mais curtas e estruturadas, atingindo um melhor nível de interface entre os níveis prosódico e segmental.

As primeiras negações produzidas pela criança foram classificadas segundo suas funções, baseadas num sistema de classificação sócio-pragmática, proposto por Beaupoil-Hourdel (2013), com as seguintes categorias: Rejeição/recusa, subdividida em recusa de uma pessoa, atividade, proposição, entidade, interrupção de uma ação ou continuidade de uma atividade. Expectativas insatisfeitas, que abrangem referências ao não/mau funcionamento de um objeto, bloqueio de uma atividade, desapontamento 
e inabilidade (da criança de realizar uma atividade). Ausência/desaparição-objetos ou pessoas que estavam anteriormente presentes, ou habitualmente presentes ou das quais se antecipava a presença de alguma maneira, mas estão ausentes. Proibição/ comando - ordens e/ou interdições que objetivam parar ou deter a criança ou ações nas quais ela está engajada. Oposição/correção - situações de desacordo entre interlocutores, negações utilizadas para indicar discordância ou contradição (somente possível para a criança quando esta começa a considerar a opinião, crenças e pressuposições de seu interlocutor). Rogativa negativa - termos com conotação negativa como onomatopeias e interjeições como eca! ou urg! ôxe! Negação epistêmica - expressão de falta de conhecimento ou afirmação de que não possui determinado conhecimento. Negação funcional - produção de uma declaração negativa para a qual se pode traçar um valor de verdade correspondente, negação dependente de interação com interlocutor, pode ocorrer como resposta a proposições, a perguntas do tipo sim/não, ou declarações.

A partir dessas categorias, procuramos, neste trabalho, discutir cada função negativa produzida pelas crianças, comparando sua emergência na fala da criança brasileira e francesa, observando quais marcadores negativos e gestos são utilizados na construção de cada função, bem como se há especificidades no desenvolvimento destas funções nas duas línguas. No que diz respeito às produções infantis, inicialmente objetivamos analisar as características das primeiras produções interpretadas como oposições, protestos e, posteriormente, como negações linguisticamente estruturadas, no período que antecede as primeiras produções da palavra 'não' foneticamente realizada enquanto tal (primeira partícula negativa produzida pela criança). Para tanto, estamos fundamentados na hipótese de que, embora não haja continuidade estrutural entre as primeiras produções infantis e suas construções linguísticas posteriores, há anterioridade funcional e significativa entre as primeiras produções interpretadas enquanto negações, e as negações que serão posteriormente estruturadas gramaticalmente.

Vasconcelos (2017) observou como as mesmas crianças observadas aqui, a partir de mais ou menos dois anos de idade, fazem uso de elementos prosódicos e não só sintáticos e morfológicos na construção de enunciados negativos. A análise dessas construções infantis num período em que há evidências de construções sintáticas mais elaboradas, com enunciados um pouco mais longos, dominam aspectos complexos de sua língua, realizando, por exemplo, proeminência entonacional de elementos deslocados e distinguindo elementos intercalados a partir de curvas prosódicas distintas, acoplados a gestos específicos (mão espalmada, gesto de apontar e outros). Nosso objetivo, aqui, é analisar os recursos utilizados pelas crianças para expressar a negação que antecedem o uso das marcas morfológicas e sintáticas de negação de sua língua materna. 


\section{Métodos e dados}

O presente estudo dedica-se ao acompanhamento longitudinal de uma criança monolíngue brasileira (falante de português), registrada, em situações naturalísticas de interação com seus familiares, com duração variável de 30 minutos a uma hora, a partir de 04 semanas aos 2 anos e 8 meses de idade. As análises focalizam o período entre 11 e 32 meses, embora características gerais das negações produzidas entre 6 e 11 meses sejam citadas,. A criança observada, V, é filho único de família de nível socioeconômico médio da cidade de Maceió-AL; além da criança-alvo, os participantes do estudo incluem adultos que interagiram com ele durante as observações.

Em seguida, dados de M., uma criança (sexo feminino) monolíngue francesa de família de nível socioeconômico médio da cidade de Paris-FR, foram também analisados. Os dados de $\mathrm{M}$. foram registrados mensalmente entre os 11 e 32 meses de idade da criança ${ }^{2}$. Cada registro possui uma hora de duração e também abarca situações naturalísticas cotidianas.

Aspectos distintos nos dois casos como a diferença de gênero e cultura entre as crianças, bem como no início do registro dos dados (6 meses para V. e 11 para M.) foram considerados; entretanto, as análises não são desenvolvidas com o objetivo de comparar diretamente o ritmo ou velocidade de desenvolvimento das duas crianças, mas cada percurso de desenvolvimento é analisado individualmente, especialmente considerando as particularidades das duas línguas em aquisição - português e francês. Análises comparativas foram realizadas longitudinalmente, isto é, contrapondo trechos dos vídeos iniciais com os de vídeos posteriores da mesma criança. Considerações que envolvem comparação entre as duas crianças foram realizadas, mas tendo tais especificidades como ressalva.

Ao todo foram analisados 43 vídeos a partir dos quais os episódios de protonegação e negação foram identificados. Destaca-se que as primeiras produções infantis não são consideradas negações em si mesmas, mas é somente a partir da interpretação adulta que tais produções são significadas estruturadas e alçadas ao nível linguístico, sendo, portanto, a partir delas que os episódios de negação são aqui delimitados.

Entretanto, mesmo segundo tal critério, a dificuldade de realizar recortes nos dados permanece, dada a indeterminação das primeiras produções infantis: indeterminação funcional (diferentes formas são empregadas aparentemente com a mesma função); indeterminação fonética (grande variação no sinal produzido pela criança); e indeterminação na significação (o mesmo significado pode ser veiculado por um número bastante variado de sinais) (SCARPA-GEBARA, 1984). Adicionalmente observam-se também variações nas interpretações realizadas pelos adultos. Estes, lidando com a gama indeterminada de sinais infantis, engajam-se em tentativas de transformação deste sinal em signo, integrando-as nas trocas diálogicas com a criança.

\footnotetext{
2 Os dados pertencem ao grupo Colaje, coordenado pela Profa. Dra. Aliyah Morgenstern e estão disponíveis na plataforma CHILDES (MORGENSTERN; PARISSE, 2012).
} 
Entretanto, estas tentativas iniciais de inserção linguística não são sempre organizadas de maneira explícita e consistente, mas a interpretação do adulto pode traduzir-se em gestos e reações às vezes ambíguas e indefinidas. Mesmo assim, é na fala adulta que os sinais indeterminados da criança encontram espaço de significação, razão pela qual são selecionadas aqui as situações nas quais o adulto interpreta as produções infantis enquanto negações.

Todos os dados aqui analisados foram transcritos a partir do programa CLAN, programa que permite o alinhamento entre cada enunciado transcrito e sua realização em vídeo e/ou áudio, possibilitando a visualização da relação entre elementos linguísticos e extralinguísticos. Os dados de $M$. encontram-se já transcritos na plataforma CHILDES em francês. Os dados de V. foram transcritos da mesma maneira no programa CLAN a partir do sistema CHILDES - "Child language data exchange system", que normatiza regras de transcrição de dados de linguagem da criança, facilitando seu compartilhamento e análise em diferentes línguas. Cada transcrição contém linhas que correspondem à transcrição ortográfica das produções dos locutores (*CHI para "criança"; *MOT para "mãe"; yyy= sequência ininteligível) e linhas que se referem às demais situações de comunicação (\%act para descrição das ações realizadas pelo adulto ou criança; \%sit para a descrição da situação de interação). Posteriormente, todas as transcrições realizadas foram convertidas do formato CLAN para o formato PHON. O programa PHON (ROSE; WAUQUIER-GRAVELINES, 2007) tem como objetivo permitir a análise de dados fonológicos, possibilitando comparações sistemáticas entre a produção alvo e a fala efetivamente produzida do ponto de vista segmental e prosódico pela criança, além de exportar segmentos de áudio para o programa PRAAT para as análises acústicas.

As vocalizações, bem como os movimentos do corpo e os gestos infantis explicitamente interpretados pelos adultos como negações foram considerados. A partir do programa PHON realizou-se a notação das ações, direção do olhar, expressões faciais e gestos realizados durante cada oposição. O contexto de cada produção foi igualmente descrito.

Inicialmente, descrevem-se os protestos, oposições e negações, conforme interpretados pelos pais, produzidos pelas crianças no período que antecede o surgimento das primeiras negações linguisticamente estruturadas (por volta dos 16 meses de idade). Em seguida, classificam-se as primeiras negações produzidas pelas crianças em funções, conforme descritas por Beaupoil-Hourdel (2013), observando se as diferentes funções negativas produzidas pelas crianças apresentam uma ordem específica de surgimento durante a aquisição, bem como se é possível relacionar determinadas funções negativas ao uso de entonações e/ou gestos específicos. 


\section{Resultados}

Primeiras produções infantis interpretadas como negações

Abordamos aqui o período de desenvolvimento de V. que recobre os momentos anteriores as suas primeiras negações linguisticamente estruturadas. Analisamos as produções iniciais infantis que são interpretadas como manifestações de desconforto, protestos, oposições e recusas pelos adultos, tais como choro, expressões faciais, gestos e vocalizações. As quais, embora possuam caráter indiferenciado e não arbitrário, sendo utilizadas em uma série de situações e contextos indistintos e de maneira não estruturada pela criança, são, desde muito cedo, interpretadas pelos adultos como expressões de 'vontades' e 'intenções' infantis, constituindo, portanto, antecedentes não verbais das construções negativas verbais em desenvolvimento. O prefixo proto marca, então, o caráter precursor (funcional e não estrutural) destas ações, interpretadas e significadas pelos adultos como negações. Deste modo, para as produções infantis aqui qualificadas como negações leia-se protonegações, salvo alguma consideração contrária tenha sido feita.

Resumidamente, no que diz respeito às negações produzidas a partir dos seis meses de idade, observam-se em 15 episódios nos quais o balbucio infantil foi interpretado pelos pais da seguinte maneira:

- 5 produções interpretadas como inabilidade (situações nas quais V. tenta alcançar objeto e não consegue), e

- 10 produções interpretadas como expectativas insatisfeitas a partir do bloqueio de uma atividade ( 8 situações nas quais a mãe afasta objeto com o qual V. brincava e 2 nas quais sua mãe impede que V. leve objeto à boca, situações nas quais a criança reage movimentando-se e balbuciando).

Tais produções caracterizam-se pela repetição de vogais, notadamente centrais e anteriores, que muitas vezes se confundem com choro infantil. Em tais situações, a criança realiza produções semelhantes a vogais em repetição; são acompanhadas por expressão de choro, tensão corporal e agitação, muitas vezes jogando o corpo para trás. Tais elementos evidenciam o caráter instável dessas produções que não parecem ainda possuir o valor distintivo de traços fônicos para a criança (mesmo que possamos distinguir sons vocálicos em suas produções). Além disso, é possível observar o surgimento das primeiras produções multissilábicas, repetidas no contexto do balbucio, embora estas pareçam apresentar o mesmo caráter indiferenciado, sem possuir ainda o valor distintivo, fonológico do adulto.

Voz e gesto são praticamente indissociáveis nessas emissões em seu efeito significativo; incluem elementos multimodais que acompanham as produções da criança como a presença de tensão corporal, movimentação do corpo e membros superiores e focalização do olhar infantil nos objetos presentes no ambiente, sem focalizar seu olhar sobre sua mãe ou pai, adultos com quem interage, mesmo quando estes se encontram diante dele. 
As ilustrações a seguir são retiradas de vídeo realizado neste período e ilustram os elementos acima descritos. No próximo exemplo (Episódio 04), V. tenta alcançar brinquedo que sua mãe havia depositado intencionalmente fora de seu campo de alcance, na intenção de fazê-lo engatinhar para alcançá-lo. Como V. parece incapaz de fazê-lo, e não tem sucesso em obter o objeto, estende os braços, elevando seu corpo e o pescoço, olhando para o objeto e vocalizando, ações são interpretadas por sua mãe como protesto.

\section{Episódio 04 - V. tenta alcançar brinquedos (16-06-12 / 6 meses)}

$1-{ }^{*} \mathrm{CHI}: 0$.

2 - \%act: CHI olha para o brinquedo e estica o braço enquanto balança o corpo em direção a ele.

3 - *MOT: cadê filho?

4 - *MOT: vai!

5 - *CHI: 0.

6 - \%act: CHI olha para o brinquedo enquanto estica o braço e bate no chão

7 - *MOT: eita!

8 - *CHI: yyy .

9 - \%act: CHI olha para o lado em direção a outro brinquedo, move o corpo em direção ao brinquedo e vocaliza

10 - \%sit: o brinquedo para o qual CHI olha tem o desenho de um leão.

11 - *MOT: cadê o leão?

12 - *MOT: como é que o leão faz?

13 - \%act: MOT imita o rugido de um leão

$14-{ }^{*} \mathrm{CHI}:$ yyy .

15 - \%act: CHI estica o corpo e toca em um brinquedo, afastando-o para mais longe

16 - *MOT: é!

17 - *MOT: diga eu não tô(estou) gostando não disso.

Figura 1 - V. tenta alcançar brinquedos (16-06-12 / 6 meses $)^{3}$

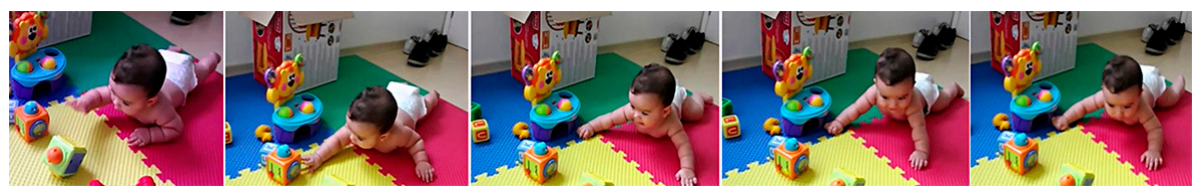

Fonte: elaboração própria

A mãe de V. interpreta que a criança está descontente com a situação (linha 17), incentivando-o a tentar alcançar o brinquedo. Destaca-se o modo como a mãe de V. inicia seu enunciado com o verbo 'diga' (linha 17). Deste modo, ela propõe à criança

Ilustração referente à transcrição apresentada acima no qual observa-se como V. tenta alcançar objeto sem sucesso (duas primeiras imagens da esquerda pra direita), elevando o corpo, focalizando o olhar sob o objeto e vocalizando (três últimas imagens) 
um canal linguístico alternativo (um enunciado inteiro) para expressar negação, através da encenação de um pequeno diálogo entre a mãe (diga) e a criança (eu não tô(estou) gostando não disso), em que o ponto de vista de ambos se alternam na sua própria fala, atribuindo à criança uma fala negativa (CAVALCANTE, 1999). Deste modo, ações infantis indiferenciadas (vocalizações que se repetem de maneira mais ou menos regular em diferentes situações) são interpretadas e reinterpretadas de maneira constante pela mãe. Assim, às indeterminações funcionais, fonéticas e semânticas das produções infantis, aliam-se também variações nas interpretações realizadas pelos adultos. Estes, lidando com a gama indeterminada de sinais infantis, engajam-se em tentativas de transformação deste sinal em signo linguístico.

Dos 7 aos 9 meses, observam-se três situações nas quais V. começa a fazer uso de qualidade de voz diferenciada (rangido) em produções interpretadas por seus pais como negações. Por volta dos 07 meses de idade, as produções de V. parecem se complexificar, pois suas vocalizações começam a apresentar novas características (alteração da qualidade de voz) que as distanciam do choro, sendo acompanhadas por alteração na interpretação adulta, que atribuem intenção negativa a este tipo de produção da criança. Em adição, sua produção gestual também se modifica, pois passa a agir de maneira mais particularizada e adaptada a cada situação. Neste episódio, por exemplo, quando o pai de V. tenta tirar o pedaço de pão de suas mãos, V. puxa o pão com as duas mãos tirando-o da boca e afastando-o do pai, em reação que apresenta direção e intenção diretamente oposta à do pai.

Figura $2-$ V. vocaliza e segura o pão
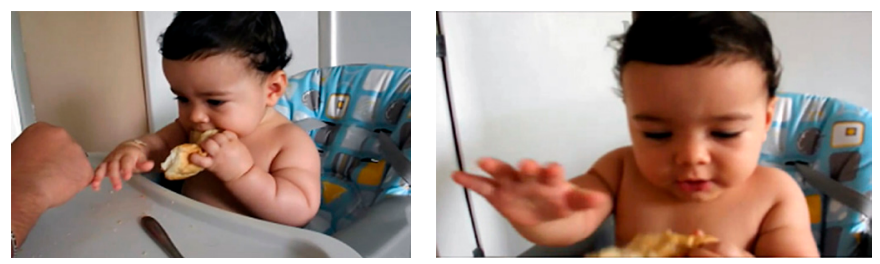

Fonte: Elaboração própria.

Em tais situações, a criança reage de maneira integrada sincronizando produção vocal (voz rangida), ação (afastando o objeto ao mesmo tempo em que afasta a mão do adulto) e a direção do olhar (alternando seu olhar entre o objeto e o adulto), em produção complexa interpretada como negação.

Já com relação aos dados de $\mathrm{M}$, como seus registros foram iniciados mais tardiamente, comparando-se aos de V. Só dois vídeos abarcam este período, um realizado aos 10 e um segundo aos 11 meses de idade.

Na primeira imagem (da esquerda para direita), V. vocaliza e segura o pão com a mão esquerda, ao mesmo tempo em que tenta afastar a mão do pai com sua mão direita. Na segunda imagem, de maneira semelhante, V. usa uma das mãos para segurar o pão e com a outra afasta a mão da mãe. 
Episódio 10 - M. tenta subir as escadas (20-02-06/ 10 meses)

1. *CHI: 0 .

2. \%act: CHI engatinha em direção a escada.

3. *CHI: dada

4. \%act: $\mathrm{CHI}$ engatinha em direção a escada.

5. \%obs: MOT conversa com a observadora sobre um brinquedo da criança.

6. *CHI: 0 .

7. \%act: CHI para com uma mão do degrau da escada, apoiando-se nela e olha para a

8. Observadora.

9. *CHI: da \# baba dada.

10. \%act: $\mathrm{CHI}$ olha para frente novamente, começa a subir a escada

11. *MOT: Madeleine Madeleine

12. *OBS: subir as escadas ${ }^{5}$

13. *CHI: 0 .

14. \%act: para de subir as escadas, olha para a mãe.

15. *MOT: não

16. \%act: MOT faz gesto de negação com a cabeça.

17. *CHI: 0 .

18. \%act: Olha para frente, começa a descer as escadas.

19. *MOT: isso, descemos ${ }^{7}$

20. *OBS: Funciona como tobogã ao mesmo tempo, é bom ${ }^{8}$

21. CHI: 0 .

22. \%act: volta a subir as escadas, sobe o primeiro degrau, mas para e volta-se para a mãe.

23. *MOT: [=! risos] Ela passa todo o tempo subindo e descendo ${ }^{9}$

24. \%act: olhando para a OBS.

25. *MOT: Não \# nós descemos ${ }^{10}$

26. \%act: realiza gesto de negação com a cabeça.

27. *CHI: 0 .

28. \%act: $\mathrm{CHI}$ desce as escadas.

A mãe de M. procura atrair a atenção da criança chamando-a pelo nome duas vezes utilizando entonação ascendente (linha 10), M. então se vira e olha para mãe (linha 13):

\footnotetext{
Original: monter les escaliers

6 Original: non

Original: non \# voilá on descend

8 Original: ça fait toboggan au meme temps \#c'est bien.

9 Original: elle passe tout le temps à monter et à descendre

10 Original: Non \# on descend
} 
Figura 3 - M. tenta subir as escadas (20-02-06/ 10 meses $)^{11}$
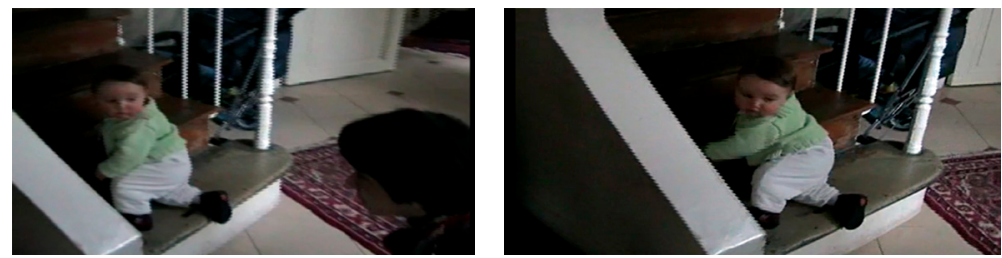

Fonte: Elaboração própria.

A mãe da criança enuncia 'non' com entonação plana e realiza gesto de negação com a cabeça (linha 14), em seguida repete a palavra 'non'(linha 18). M. reage descendo as escadas, como se compreendesse a negação da mãe (linha 17).

Logo em seguida M. volta a subir as escadas, mas interrompe a ação, vira-se e olha para a mãe novamente, como havia feito anteriormente, apesar de sua mãe não tê-la chamado. Neste momento, M. parece antecipar oposição da mãe já aos 11 meses de idade interrompendo sua ação e esperando pela reação da mãe (Linha 21), que efetivamente enuncia 'non' novamente realizando gesto negativo com a cabeça (Linha 24). M. então desce as escadas (Linha 28).

A mãe da criança interpreta que ela já compreende que não deve subir as escadas, por isso repete a ação tentando subir no primeiro degrau e descendo-o várias vezes durante o dia, segundo seus relatos. A criança parece de fato antecipar a oposição da mãe, interrompendo sua ação e olhando para ela, antes de sua negação.

No que diz respeito às produções de M., observa-se como a criança realiza pequenas ações interpretadas como negações, como por exemplo, puxar um livro e retirá-lo da mão de sua mãe. Nesta situação, a mãe da criança tenta folhear e mostrar o livro, enquanto M. tenta recuperá-lo.

Episódio 11 - M. tenta recuperar o livro que sua mãe segura (20-02-06/ 11 meses)

*MOT: ó, isto é amarelo \# amarelo ${ }^{12}$

\%act: abre o livro diante de CHI e mostra imagem da cor amarela.

*CHI: 0.

\%act: com a mão esquerda pega o livro e o puxa, tentando o retirar de sua mãe, mas ela não o solta

*MOT: uma panela azul ${ }^{13}$

\%act: vira a página do livro e mostra imagem da cor azul

*CHI: 0.

\%act: puxa o livro novamente com a mão esquerda e o retira da mão da mãe.

\footnotetext{
11 À direita, M. vira-se e olha para mãe que acaba de chamar sua atenção. À esquerda, M. sobe as escadas pela segunda vez, mas para e olha para sua mãe.

12 Original: oh ça c'est jaune \# jaune

13 Original: une casserole bleu.
} 
Figura 4 - M. puxa o livro afastando-o de sua mãe.
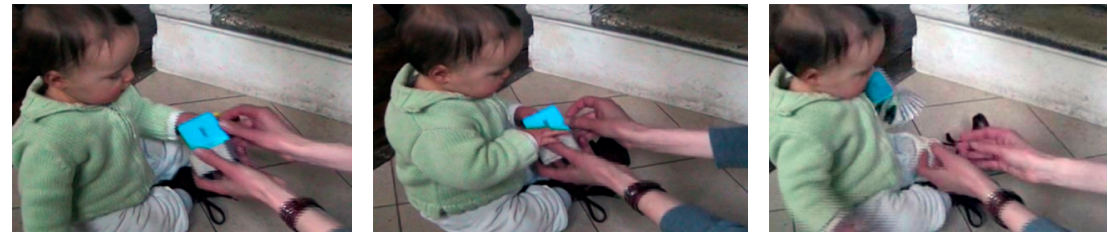

Fonte: Elaboração própria.

Do mesmo modo como descrito em situação semelhante com V., quando os pais tentam retirar um pedaço de pão da criança, aqui também é possível interpretar que a produção gestual de M. se complexifica, visto que a criança age de maneira particularizada e adaptada à situação, puxando o objeto e ao mesmo tempo tentando afastar a mão da mãe, em reação que apresenta direção e intenção diretamente oposta à da mãe. M., fazendo uso neste momento de ações para exprimir negação, ocupa papel ativo na interação.

As produções de V. e M., aqui consideradas como manifestações de desconforto, protestos e oposições, dos 6 aos 16 meses de idade, inicialmente são caracterizadas por balbucios e ações genéricas. Embora não possuam ainda função especializada, não sendo nem mesmo necessariamente dirigidas aos pais, tais manifestações são, entretanto, sistematicamente interpretadas pelos pais como 'reclamações e oposições infantis'. Chamamos tais produções de "protonegações", constituindo parte inicial das produções negativas em desenvolvimento. Ao longo do período aqui analisado, estas produções passam por transformações, começando a apresentar novas características, como a adição de qualidade vocal distinta e produção gestual mais particularizada e adaptada a cada situação. Destaca-se, ainda nos momentos iniciais do processo de aquisição da linguagem, como essas crianças começam a coordenar ações verbais e não verbais, o que torna suas produções mais compreensíveis para o adulto. Esta observação corrobora as afirmações de Balog e Bretanti (2008), segundo os quais as crianças já coordenam suas produções verbais e não verbais nos níveis temporal e direcional no período de produção de uma palavra.

É possível, portanto, afirmar que, apesar de os dados de M. serem reduzidos quando comparados aos de V. durante o primeiro ano de vida, a partir deles é possível corroborar observações realizadas com V. As análises destacam pontos em comum como a observação de que por volta do fim do primeiro ano de vida, as duas crianças fazem uso de gestos mais particularizados e adaptados a cada situação, sincronizando produção vocal e gestual. Como exemplo, veja-se como tanto M. quanto V. passam a puxar objetos para afastá-los dos adultos ou afastar a mão do adulto de objetos, em ações que apresentam direção e intenção diretamente opostas às do adulto, às vezes acompanhadas de vocalizações, ações estas interpretadas como negações. Deste modo, passam a ocupar papel mais ativo na interação, agindo e não só reagindo aos pais. Por volta deste período, ambas as famílias parecem interpretar também que as crianças começam a compreender negações e proibições formuladas pelos adultos. 
Objetivam-se classificar, nesta seção, as produções negativas verbais e gestuais produzidas pelas crianças de acordo com suas funções, conforme classificadas por Beaupoil- Hourdel, Morgenstern e Boutet (2016). A partir dessa classificação, observase como grande parte das produções de V. são classificadas como rejeição/recusa (40 produções), situações nas quais os pais interpretam que V. rejeita uma proposição como tomar banho ou emprestar um brinquedo, por exemplo. As rejeições de V. foram produzidas principalmente através da palavra 'não' ou aproximações desta palavra como ' $\tilde{a}$ ' e ' $n \tilde{a}$ '. Somente a partir dos 29 meses de idade as funções das produções negativas de V. começam a diversificar-se. Neste momento surgem oposição/correção (14), proibição/comando (3), negação epistêmica (3) e ausência/desaparição (1). A seguir tabela resumida com as produções de V.:

Tabela 1 - Resumo da categorização funcional e prosódica das produções negativas de $\mathrm{V}$

\begin{tabular}{|c|c|}
\hline Produção (quantidade) & Função \\
\hline $\begin{array}{l}\text { Variações de sons próximos ao 'não' (28) } \\
\text { Não (8) } \\
\text { “rangido" (3) } \\
\text { Esse não (1) }\end{array}$ & $\begin{array}{l}\text { Rejeição/ } \\
\text { Recusa }\end{array}$ \\
\hline $\begin{array}{l}\text { Não não (5) } \\
\text { a não } \\
\text { nenê foi não (em)bora } \\
\text { um não não mamãe } \\
\text { não não não vô parece um um um pinóquio não } \\
\text { não não vou não } \\
\text { não cai não cai não } \\
\text { a mamãe a mamãe fez ti ti ti ti ti amo não } \\
\text { não não fez ti ti ti amo ta mim não } \\
\text { não fez ta mim }\end{array}$ & $\begin{array}{l}\text { Oposição/ } \\
\text { correção }\end{array}$ \\
\hline $\begin{array}{l}\text { Num sei } \\
\text { A num sei mamãe } \\
\text { Sei mamãe }\end{array}$ & Negação epistêmica \\
\hline $\begin{array}{l}\text { Assim não (2) } \\
\text { É não abi a boca }\end{array}$ & $\begin{array}{l}\text { Proibição/ } \\
\text { comando }\end{array}$ \\
\hline Sem a vaquinha & $\begin{array}{c}\text { Ausência/ } \\
\text { Desaparição }\end{array}$ \\
\hline
\end{tabular}

Fonte: Elaboração própria. 
Tabela 2 - Resumo das produções negativas de V. por mês a partir dos 11 meses $^{14}$

\begin{tabular}{l|l}
\hline \multicolumn{1}{c|}{ Mês (total de negações) } & \multicolumn{1}{c}{ Funções negativas (quantidade) } \\
\hline 14 meses (3) & Rejeição/recusa (3) \\
\hline 15 meses (13) & Rejeição/recusa (13) \\
\hline 16 meses (18) & Rejeição/recusa (18) \\
\hline 19 meses (3) & Rejeição/recusa (3) \\
\hline 29 meses (9) & $\begin{array}{l}\text { Rejeição/recusa (3) Oposição/correção (2), ausência/ } \\
\text { desaparição (1), negação epistêmica (3) }\end{array}$ \\
\hline 30 meses (3) & Proibição/comando (3) \\
\hline 31 meses (10) & Oposição/correção (10) \\
\hline 32 meses (2) & Oposição/correção (2) \\
\hline
\end{tabular}

Fonte: Elaboração própria.

De maneira geral, as negações de V. neste período são inicialmente utilizadas para rejeitar e opor-se às proposições e ações parentais; entretanto, posteriormente (a partir dos 29 meses de idade), a criança começa a produzir negações epistêmicas, funcionais e de ausência/desaparição, produzindo, portanto, proposições negativas e não somente reagindo às proposições de seus pais. Neste momento, a criança realiza constatações sobre si mesma e seu desconhecimento (negação epistêmica) e constatações sobre ausência de objetos do ambiente (ausência/desaparição). Observa-se então o desenvolvimento das negações infantis não somente a partir de sua complexificação linguística, mas também a partir do desenvolvimento das funções negativas utilizadas, que passam de reações às ações parentais a proposições negativas. Vasconcelos e Leitão (2016) chegam a resultados semelhantes a partir da análise de oposições infantis, concluindo que há deslocamento do lugar discursivo atribuído à criança, que deixa de ser posicionada apenas no lugar de oponente, para ocupar também o lugar de proponente na interação, agindo sobre o ambiente a partir de um 'ponto de vista próprio'. Neste momento, a criança não só reage conforme as situações criadas pelos pais, mas toma a iniciativa de agir, mobilizando aspectos do ambiente em proposições muitas vezes negativas.

Quanto às produções da criança francesa, um grande número de negações pode ser observado. Para este trabalho, 462 negações de M. foram consideradas, ressaltando-se que este número elevado é também consequência da quantidade e tamanho dos vídeos franceses, que ultrapassam os brasileiros.

14 Ressalta-se que houve meses nos quais não foram registradas negações, por isso nem todos estão presentes na tabela, mas somente aqueles nos quais produções negativas foram registradas. 
Grande parte das negações de M. são rejeição/recusa (115 negações), sendo esta também a função mais frequentemente produzida pela criança brasileira, seguida por expectativas insatisfeitas (inabilidade/falha) (86), oposição/correção (77), negação funcional (74), negação epistêmica (65), ausência/desaparição (29), proibição/ comando (14) e rogativa negativa (2). Observa-se, deste modo, grande variedade nas funções negativas utilizadas pela criança. A seguir tabela que apresenta de maneira resumida as produções de $\mathrm{M}$.

Tabela 3 - Resumo da categorização funcional e prosódica das produções negativas de $\mathrm{M}$.

\begin{tabular}{|c|c|}
\hline Produção (quantidade) & Função \\
\hline $\begin{array}{l}\text { Não (71) } \\
\text { Enunciado com não (18) } \\
\text { Enunciado sem não (16) } \\
\text { Não em repetição (10) }\end{array}$ & $\begin{array}{l}\text { Rejeição/ } \\
\text { Recusa }\end{array}$ \\
\hline $\begin{array}{l}\text { Enunciado sem não (59) } \\
\text { Não (21) } \\
\text { Enunciado com não (5) } \\
\text { Não em repetição (1) }\end{array}$ & Expectativas insatisfeitas \\
\hline $\begin{array}{l}\text { Não (30) } \\
\text { Enunciado sem não (24) } \\
\text { Enunciado com não (21) } \\
\text { Não em repetição (2) }\end{array}$ & $\begin{array}{l}\text { Oposição/ } \\
\text { correção }\end{array}$ \\
\hline $\begin{array}{l}\text { Não (42) } \\
\text { Enunciado sem não (31) } \\
\text { Enunciado com não (1) }\end{array}$ & Negação funcional \\
\hline $\begin{array}{l}\text { Enunciado (56) } \\
\text { Não (9) }\end{array}$ & Negação epistêmica \\
\hline $\begin{array}{l}\text { Enunciado (25) } \\
\text { Não (4) }\end{array}$ & Ausência/ desaparição \\
\hline $\begin{array}{l}\text { Enunciado (11) } \\
\text { Não (3) }\end{array}$ & $\begin{array}{l}\text { Proibição/ } \\
\text { comando }\end{array}$ \\
\hline $\begin{array}{l}\text { Berk } \\
\text { Euh euh }\end{array}$ & Rogativa Negativa \\
\hline
\end{tabular}

Fonte: Elaboração própria.

Apresenta-se tabela resumida com as funções negativas de M. produzidas por mês: 
Tabela 4 - Resumo das produções negativas de M. por mês ${ }^{15}$

\begin{tabular}{|c|c|}
\hline Mês (total de negações) & Funções negativas (quantidade) \\
\hline 16 meses (2) & Rejeição/recusa (2) \\
\hline 19 meses (17) & $\begin{array}{l}\text { Rejeição/recusa (9), ausência/desaparição (4), expectativas } \\
\text { insatisfeitas (3), negação epistêmica (1) }\end{array}$ \\
\hline 21 meses (2) & Rejeição/recusa (2) \\
\hline 22 meses (24) & $\begin{array}{l}\text { Rejeição/recusa (16), oposição/correção (3), ausência/desaparição } \\
\text { (3), expectativas insatisfeitas (2) }\end{array}$ \\
\hline 23 meses (16) & $\begin{array}{l}\text { Rejeição/recusa (14), expectativas insatisfeitas (1), oposição/ } \\
\text { correção (1) }\end{array}$ \\
\hline 25 meses $(55)$ & $\begin{array}{l}\text { Oposição/correção (14), ausência/desaparição (14), rejeição/ } \\
\text { recusa (12), Expectativas insatisfeitas (8), negação funcional (7) }\end{array}$ \\
\hline 26 meses (18) & $\begin{array}{l}\text { Expectativas insatisfeitas (6), negação funcional (3), negação } \\
\text { epistêmica (3), rejeição/recusa (3), oposição/correção (3) }\end{array}$ \\
\hline 27 meses (46) & $\begin{array}{l}\text { Negação funcional (13), oposição/correção (11), negação } \\
\text { epistêmica (7), expectativas insatisfeitas (6), rejeição/recusa (5), } \\
\text { ausência/desaparição (2), proibição/comando (1) }\end{array}$ \\
\hline 28 meses (56) & $\begin{array}{l}\text { Negação funcional (20), negação epistêmica (19), proibição/ } \\
\text { comando (6), rejeição/recusa (5), oposição/correção (5), ausência/ } \\
\text { desaparição (1) }\end{array}$ \\
\hline 29 meses (82) & $\begin{array}{l}\text { Expectativas insatisfeitas (42), negação funcional (14), rejeição/ } \\
\text { recusa (11), oposição/correção (6), negação epistêmica (4), } \\
\text { proibição/comando (2), ausência/desaparição (2), rogativa } \\
\text { negativa (1) }\end{array}$ \\
\hline 30 meses (42) & $\begin{array}{l}\text { Negação epistêmica (15), rejeição/recusa (13), expectativas } \\
\text { insatisfeitas (7), oposição/correção (6), negação funcional (3) }\end{array}$ \\
\hline 31 meses $(71)$ & $\begin{array}{l}\text { Oposição/correção (23), negação epistêmica (13), negação } \\
\text { funcional (12), expectativas insatisfeitas (9), rejeição/recusa (6), } \\
\text { proibição/comando (5), ausência/desaparição (3) }\end{array}$ \\
\hline 32 meses (29) & $\begin{array}{l}\text { Rejeição/recusa (16), oposição/correção (5), negação epistêmica } \\
\text { (3), expectativas insatisfeitas (2), negação funcional (2), Rogativa } \\
\text { negativa (1) }\end{array}$ \\
\hline
\end{tabular}

Fonte: elaboração própria

Observando as produções das duas crianças (brasileira e francesa), concluímos que, independentemente da língua, a função rejeição/recusa é a primeira a ser expressa, conforme também observado por estudos clássicos sobre a tipologia e aquisição da

15 Ressalta-se que houveram meses nos quais não foram registradas negações, por isso nem todos estão presentes na tabela, mas somente aqueles nos quais produções negativas foram registradas. 
negação (BLOOM, 1970; PEA, 1980). De certo modo, esta conclusão é esperada, visto que funções como ausência/desaparição, por exemplo, muitas vezes necessitam de estruturas sintáticas complexas em sentenças com mais de uma palavra para serem expressas, enquanto a rejeição é frequentemente produzida através de gestos e marcadores linguísticos simples como 'não'. Segundo Pea (1980) a rejeição pode ser observada de maneira não-verbal já a partir dos 8 meses de idade.

Nos dados aqui analisados, a rejeição é inicialmente expressa pela criança francesa a partir de marcadores simples como 'non'. O marcador de negação 'pas' surge na expressão da rejeição a partir dos 23 meses em enunciados como "non pas avec (bro) colis" (= não com o brócolis) quando a criança rejeita comida oferecida pela mãe. Expressões mais complexas como "je veux pas" (= eu não quero) surgem aos 25 meses, com a utilização de pronome pessoal je (= eu). Ressalta-se que é exatamente aos 25 meses que o pronome pessoal je emerge nas produções de $\mathrm{M}$. e que a utilização do pronome moi atinge seu pico (93 produções), conforme relatado por Dodane e MassiniCagliari (2010), contribuindo para o desenvolvimento da negação, permitindo à criança posicionar-se na interação e construir seu ponto de vista.

Para a criança brasileira, a expressão da rejeição começa também com produções que se aproximam do não como ' $n a$ ' e ' $\tilde{a}$ ' e o 'não' que é foneticamente produzido aos 16 meses. A expressão da negação de V. se complexifica aos 29 meses com o enunciado 'esse não' quando a criança utiliza o pronome demonstrativo esse para fazer referência ao objeto específico que rejeita (neste caso um brinquedo oferecido por sua mãe). A utilização de pronomes pessoais nas negações registradas de V. é observada mais tardiamente, aos 29 meses, quando a criança enuncia "a num sei mamãe" utilizando a vogal 'a' como preenchedor (filler) que substitui o pronome pessoal 'eu'.

A função ausência/desaparição é expressa apenas uma vez pela criança brasileira durante o período observado, e é bastante tardia ${ }^{16}$, : trata-se da expressão "sem a vaquinha", aos 29 meses, quando V. procura por vaquinha de brinquedo sem encontrála. Neste momento a criança lança mão de recursos léxico-sintáticos num enunciado mais complexo do que aqueles utilizados na rejeição/recusa.

Em francês, a ausência é expressa a partir de marcadores simples como "non" e expressões mais complexas como 'a plus 'em “y a plus p(l)us poussin” (não há mais pintinhos) quando M. procura por pintinhos de pelúcia aos 19 meses. São expressões bastante formulaicas ainda, isto é, não há fortes evidências de elaboração sintática mais sofisticada. Posteriormente, a criança utiliza expressões com o marcador 'pas' (Il y a pas - y a pas toboggan - não tem tobogã, só aos 25 meses) e combinações com outros itens lexicais 'y en a pas' e 'y a plus' (não há, não há mais). Apesar de ser capaz de uso intenso, vocal e gestualmente, vinculado à função rejeição/recusa, só mais tarde a criança usa recursos lexicais e morfossintáticos da língua materna para expressar tal função.

16 Diferentemente de outros sujeitos cuja fala foi analisada em trabalhos sobre o português brasileiro, como De Lemos (1987), com o par ó/ bô (olha, acabou) para aparição/ ausência surgindo bem cedo na fala da criança. 
A expressão da função expectativas insatisfeitas não surgiu nos registros em português. Em francês, ela foi incialmente expressa através do marcador 'non', sendo muitas vezes utilizada quando a criança não conseguia realizar determinada ação. Negações epistêmicas surgem nas produções da criança brasileira aos 29 meses através das expressões 'num sei' e 'a num sei mamãe'17.

Nos dados de M. observamos inicialmente o enunciado "sais pas" como forma de expressão da negação epistêmica aos 19 meses de idade. Destaca-se ausência do pronome pessoal je e do marcador de negação 'ne' nesta sentença. Ressalta-se, entretanto, que no francês falado atualmente, de fato a partícula ne já não é produzida; isto é, a negação em francês está em processo de mudança linguística (ASHBY, 2001). M. parece ser sensível a essa mudança, pois aos 27 meses ela produz enunciados como "moi je sais pas chanter" (eu não sei cantar) acrescentando predicado através do qual especifica aquilo que ela afirma 'não saber'. Aos 28 meses ela produz negações epistêmicas sobre o desconhecimento de terceiros, neste caso de seu irmão mais novo com apenas poucos meses de vida - Comme i(l) sait pas encore parler (ele não sabe ainda falar). Deste modo realiza suposições e afirmações sobre terceiros e não só sobre si mesma.

No que diz respeito à função proibição/comando, esta surge nas produções da criança brasileira quando V. repete proibições enunciadas por seu tio "é não abi a boca" e "assim não" aos 30 meses de idade. Nos dados de M., as proibições são majoritariamente produzidas através do uso da partícula 'pas' - 'pas là faut me faire au photo' (não aqui não pode tirar minha foto) aos 28 meses, quando proíbe a observadora de realizar filmagens na rua. Em português a oposição/correção é majoritariamente produzida a partir do marcador 'não' (sozinho ou em repetição), bem como enunciados complexos que buscam negar de maneira explícita o elemento afirmado pela mãe. Por exemplo, aos 29 meses, V. produz a seguinte negação "nenê foi não (em)bora" após a mãe afirmar que a chupeta da criança havia 'ido embora'. Nas produções de M. a oposição é também produzida a partir do marcador "non". Posteriormente a criança introduz o 'pas' também se opondo a afirmações do adulto como, por exemplo, " $i(l)$ dort pas" (ele não está dormindo), produzida pela criança aos 25 meses de idade em oposição a afirmação da observadora de que o ursinho de pelúcia estava dormindo.

Por fim, a função negação funcional não foi observada nos dados registrados da criança brasileira. Nos dados de M., esta função foi majoritariamente produzida a partir do marcador 'non' em resposta a perguntas do tipo sim/não de sua mãe.

De maneira geral, observam-se semelhanças no desenvolvimento das produções das duas crianças como, por exemplo, a complexificação progressiva das negações produzidas através da inclusão de pronomes pessoais em suas sentenças, bem como através da introdução de variações nas partículas negativas utilizadas. No que diz

17 Ramos (2006) duas formas, uma "plena" (não) e outra "reduzida" (num) do marcador de negação; esta constitui a forma "fraca" ou "reduzida", pois não ocorre em posição final na sentença, mas somente pré-verbal e em co-ocorrência com outros marcadores de negação (presença do item pleno não na mesma sentença e/ou presença de quantificadores do tipo "ninguém", "nada" na mesma sentença). 
respeito às funções utilizadas, observa-se também o surgimento da rejeição/recusa como primeira função produzida pelas duas crianças e o desenvolvimento das funções negativas utilizadas, que passam de reações às ações parentais a proposições negativas nos dois casos (VASCONCELOS; LEITÃO, 2016).

\section{Considerações finais}

A partir do estudo do desenvolvimento da negação na fala dos sujeitos, buscou-se entender melhor questões concernentes ao estatuto do período chamado pré-linguístico de desenvolvimento, que antecede o estabelecimento de léxico inicial, bem como entender como as funções de negação emergem e se se tornam mais complexas e especializadas, mesmo com um léxico bastante restrito.

Neste período elementos multimodais acompanham as produções da criança como, por exemplo, presença de certa tensão corporal, movimentação do corpo e membros superiores e focalização do olhar infantil nos objetos presentes no ambiente (objeto com o qual brinca, objeto que tenta alcançar ou objeto que tenta levar à boca), sem focalizar seu olhar sobre o adulto com quem interage mesmo quando este se encontra diante da criança. Já as primeiras produções infantis que foram interpretadas como protestos, por volta dos 6 meses de idade, são caracterizadas pelo balbucio. Tais produções são semelhantes a vogais em repetição (/a/), acompanhadas por expressão de choro, tensão corporal e agitação e, embora apresentem caráter instável e não estruturado, são frequentemente interpretadas pelos adultos como expressões de "vontades" e "intenções" infantis.

A produção gestual e vocal da criança modifica-se. Os gestos tornam-se mais complexos, visto que as crianças passam a agir diretamente sobre objetos foco de seu interesse (puxando ou afastando objetos, por exemplo), bem como diretamente sobre os adultos (por exemplo, afastando a mão da mãe e pai em situações de rejeição), em reação que apresentava direção e intenção diretamente oposta à do adulto, agindo, portanto, de maneira mais especializada e adaptada às situações.

As vocalizações iniciais começam a apresentar novas características que as diferenciam do choro, como a utilização de diferentes qualidades de voz (por exemplo a voz rangida utilizada pela criança brasileira) e outros elementos como repetições silábicas. Ao longo do tempo, observou-se como as crianças passaram a sincronizar produção vocal (choro, grito, voz rangida), ação (afastar objetos, afastar-se dos pais) e direção do olhar (alternando olhar entre o objeto e o adulto) em produções interpretadas como negações. Estas observações parecem corroborar o trabalho realizado por Balog e Brentari (2008), mostrando como ainda nos momentos iniciais do processo de aquisição da linguagem, as crianças começam a coordenar ações verbais e não verbais, tornando suas produções mais diretamente compreensíveis . Conclui-se, deste modo, como as ações e vocalizações infantis auxiliam na delimitação de um todo significativo e no começo da estruturação que indicia o estabelecimento de uma ponte entre som e sentido. 
Deste modo, as análises aqui construídas tocam especificamente no tema da continuidade/descontinuidade linguística, conforme formulado por Jakobson e discutido por Scarpa (2005). Conforme os dados aqui observados, embora não seja possível afirmar a existência de continuidade estrutural entre as primeiras produções infantis e suas construções linguísticas posteriores, há anterioridade funcional e significativa entre as primeiras produções interpretadas enquanto negações, e as negações que serão posteriormente estruturadas gramaticalmente. Tal anterioridade parece ser constituída pela interpretação adulta que atribui sentido e função simbólica às produções infantis. Essa estruturação ocorre na medida em que a mãe imprime/interpreta sentido às produções infantis a partir de elementos linguísticos. Quando a mãe diferencia, por exemplo, o que ela caracteriza como 'choro' - produzido de modo rítmico e duradouro, do 'choramingo' - semelhante ao choro, mas apresentando menor altura e duração, com elevações súbitas e ritmo descontínuo. Essa distinção fundamenta-se em critérios prosódicos de ritmo e duração, conforme apontado por Vasconcelos e Leitão (2016), Freitas (2012) e Cavalcante (1999), atribuindo função simbólica ao choro, na medida em que sistematiza critérios linguísticos de distinção e valoração, produzindo sentido a partir dele. Deste modo, o adulto já imprime função simbólica a partir de critérios linguísticos às primeiras produções infantis. Esse processo promove significativos impactos no desenvolvimento infantil, levando-nos a questionar a separação estrita entre períodos pré-/proto-linguístico e linguístico, bem como a compreensão de elementos extralinguísticos como 'não-linguísticos', visto que estes participam do processo de inserção do falante, via discurso materno, na língua.

NUNES DE VASCONCELOS, A.; SCARPA, E.; DODANE, C. Negative expressions in the speech of one Brazilian and one French child. Functions and prosodic characteristics. Alfa, São Paulo, v. 63, n.2, p.349-371, 2019.

- ABSTRACT: This work is a longitudinal study of two children, one Brazilian and the other French. It focuses on the development of the expressions of negation in their early speech. It aims at showing that, in the beginning, gesture and vocalization are indissociable and they are provided with meaning through the other's interpretation. We call those expressions "protonegation". The functions of the first negative particles uttered by the children are based on the socio-pragmatic classification system of negation developed by Beaupoil-Hourdel (2013). The following categories are considered: rejection/ refusal; failed expectations; absence/ disappearance; prohibition/command; opposition/correction; negative pleading; epistemic negation; functional negation. The results show that rejection/ refusal was the first function to emerge in the speech of both children whereas absence/disappearance was rather late.. The progressive complexity of the negations may be dependent on, the introduction of personal pronouns in the child's utterances, and on more syntactic and lexical complexity, independently of the target language. On the other hand, actions and vocalizations by the children contribute to the delimitation of a meaningful whole, even with a rather restricted lexicon.,

- KEYWORDS: Language Acquisition. Negation. Portuguese. French. 


\section{REFERÊNCIAS}

ASHBY, W. J. Un nouveau regard sur la chute du ne en français parlé tourangeau : s'agit-il d'un changement en cours? Journal of French Language Studies, Cambridge, v. 11, n. 1, p. 1-22, 2001.

BALOG, H. L.; BRENTARI, D. The relationship between early gestures and intonation. First Language, London, v. 28, n. 2, p. 141-163, 2008.

BEAUPOIL-HOURDEL, P. A multimodal and corpus-based approach to children's expression of refusal and rejection. International conference of the AFLiCO Empirical Approaches to Multi-modality and to Language Variation, Lille, p. 15-17, 2013.

BEAUPOIL-HOURDEL, P.; MORGENSTERN, A.; BOUTET, D. A Child's Multimodal Negations from 1 to 4: The Interplay Between Modalities. In: LEE, C. (org.). Negation and Polarity: Experimental Perspectives. Springer, 2016. p. 95-123.

BLOOM, L. M. Language development: form and function in emerging grammars. Cambridge: M.I.T., 1970.

BOYSSON-BARDIES, B. Comment la parole vient aux enfants. Paris: Odile Jacob, 1996.

BOYSSON-BARDIES, B.; HALLÉ, P., SAGART, L.; DURAND, C. A crosslinguistic investigation of vowel formants in babbling. Journal of Child Language, Cambridge, v. 16, n. 1, p. 1-17, fev. 1989.

CAVALCANTE, M. C. B. Da voz à língua: a prosódia materna e o deslocamento do sujeito na fala dirigida ao bebê. 1999. 239p. Tese (Doutorado em Linguística) - Instituto de Estudos da Linguagem Universidade Estadual de Campinas, Campinas, 1999.

DECASPER, A. J. et al. Fetal reactions to recurrent maternal speech. Infant behavior and development, London, v.17, n.2, p. 159-164, 1994.

DE LEMOS, C. T. G. On Ser And Estar In Brazilian Portuguese. Tübingen: Gunter Narr Verlag, 1987.

DODANE, C. A emergência da linguagem: da proto-língua as primeiras formas linguísticas. In: ENCONTRO NACIONAL SOBRE A LINGUAGEM DA CRIANÇASABERES EM CONTRAPONTO, 3., 2015, Porto Alegre. Anais [...], Porto Alegre, 2015. Conferência de abertura.

DODANE, C.; MARTEL, K. Évolution de l'inventaire de contours de Fo chez deux enfants français de 10 à 12 mois: l'importance du contexte pour décrire le stade prélinguistique. Enfance, London, v. 61, n. 3, p. 305-316, 2009. 
DODANE, C.; MASSINI-CAGLIARI, G. La prosodie dans l'acquisition de la négation: étude de cas d'une enfant monolingue francaise. ALFA: Revista de Linguística, Araraquara, v. 54, n. 2, p. 335-360, 2010.

FREITAS, S. M. da C. A internalização do sentido do não: resposta à oposição por parte de uma criança em interações protoargumentativas. Recife, 2012. Relatório final de Prática de Pesquisa I.

FRIEDERICI, A. D.; FRIEDRICH, M.; CHRISTOPHE, A. Brain responses in 4 monthold infants are already language specific. Current Biology, Cambridge, v. 17, n. 14, p. 1208-1211, 2007.

KONOPCZYNSKI, G. Le Langage Emergent II: Aspects Vocaux et Mélodiques. Hambourg: Buske Verlag, 1991.

KONOPCZYNSKI, G. Le Langage Emergent: Caractéristiques Rythmiques. Hamburg: Buske Verlag, 1990.

MORGENSTERN, A.; PARISSE, C. The Paris Corpus. Journal of French Language Studies, Cambridge, v. 22, n. 1, p. 7-12, 2012.

NAME, C. A aquisição da linguagem sob a ótica do processamento. In: CAVALCANTE, M. C. B; FARIA, E. M. B.; LEITÃO, M. (org.). Aquisição da linguagem e processamento linguístico: perspectivas teóricas e aplicadas. João Pessoa, Ideia: Editora Universitária, 2011. p. 173-196.

NAZZI T.; JUSCZYK, P.; JOHNSON, E. Language discrimination by English-learning 5-month-olds: Effects of rhythm and familiarity. Journal of Memory and Language, Maryland Heights, v. 43, n. 1, p. 1-19, 2000.

PEA, R. The Development of Negation In Early Child Language. In: OLSON, D.R. (org). The Social Foundations of Language \& Thought. New York: W.W. Norton, 1980. p. 156-186.

RAMOS, J. O processo não > num na fala. In: RAMOS, J.; VITRAL, L. (org.). Gramaticalização: uma abordagem formal. Rio de Janeiro: Tempo Brasileiro, 2006. p.119- 132 .

ROSE, Y.; WAUQUIER-GRAVELINES, S. French speech acquisition: The international guide to speech acquisition, In: McLEOD, S. (org.). The international guide to speech acquisition. Clifton Park: Thomson Delmar Learning, 2007. p. 364-384.

SCARPA, E. M. A criança e a prosódia: uma retrospectiva e novos desenvolvimentos. Cadernos de Estudos Linguísticos, Campinas, v. 46, n. 2, p. 19-28, 2005.

SCARPA, E. M. Desenvolvimento da intonação e a organização da fala inicial. Cadernos de Estudos Linguísticos, Campinas, v. 14, p. 65-84, 1988. 
SCARPA, E. M.; FERNANDES-SVARTMAN, F. Entoação e léxico inicial. Veredas, Juiz de Fora, v. 16, n. 1, p. 38-52, 2012.

SCARPA-GEBARA, E. The development of intonation and dialogue processes in two Brazilian children, 1984. 273f. Thesis (Doctor of Philosophy) - University of London, London, 1984.

VASCONCELOS, A. N. de. Emergência da negação e prosódia: estudo de casos de uma criança brasileira e uma criança francesa. 2017. 218f. Tese (Doutorado em Linguística) - Instituto de Estudos da Linguagem, Universidade Estadual de Campinas, Campinas, 2017.

VASCONCELOS, A. N. de. Argumentação e desenvolvimento cognitivo: emergência e estabilização de condutas protoargumentativas. 2013. 141 f. + DVD. Dissertação (Mestrado em Psicologia cognitiva) - Centro de Filosofia e Ciências Humanas, Universidade Federal de Pernambuco, Recife, 2013.

VASCONCELOS, A. N. de; LEITÃO, S. Desenvolvimento da protoargumentação na interação adulto-bebê. ALFA: Revista de Linguística, Araraquara, n. 60, p. 119-146, 2016.

VIHMAN, M.M. Early syllables and the construction of phonology. In: FERGUSON, C. A.; MENN, L. C. (org.). Phonological development: Models, research, implications. York Press, Monkton, MD, 1992. Chapter 13.

Recebido em 20 de novembro de 2017

Aprovado em 12 de maio de 2018 